\title{
Retractions: the good, the bad, and the ugly
}

What researchers stand to gain from taking more care to understand errors in the scientific record.

8 September 2020

Quan-Hoang Vuong

\section{Tara Moore/ Getty}

While it seems obvious that withdrawing papers, which contain errors or misconduct, helps to keep the literature healthy, researchers want to avoid retractions at all costs.

Indeed, no editorial practice in academia can affect an academic reputation as much as a retraction.

The stigma is rooted in the fear of every researcher that a retracted article, which would remain accessible online with an additional tagline of retraction notice, is like a scar seared into the public profile of an author.

But, just as every scar is a reminder of a past mistake or injury, every retraction, regardless of the reasons - an honest mistake or a deliberate fraud, also has something to teach us. 


\section{The good}

A recent analysis of 2,046 retraction records, cleaned upon extraction from the Retraction Watch (RW) Database and major publishers' websites, brings attention to how retractions are not always initiated by the editors and publishers, but also by the authors themselves.

As Figure 1 shows below, although half of the retraction notes do not reveal the initiators, 301 notices, or $15 \%$, were made solely by the authors.

These 'heroic souls', despite knowing the stigma associated with a retracted article, willingly make that request and even provide reasons for why they think the findings should be removed from the literature.

If between 2008 and 2016, the number of such 'heroic acts' was consistently below 10 each year, by 2017 and 2018, it had spiked to 27 and 55, respectively.

At first look, this could spark concerns about the rising number of inadequate publications. Yet, one should also be hopeful that the competitive world of academia has not completely extinguished scientists' motivations for genuine selfcorrection and transparency.

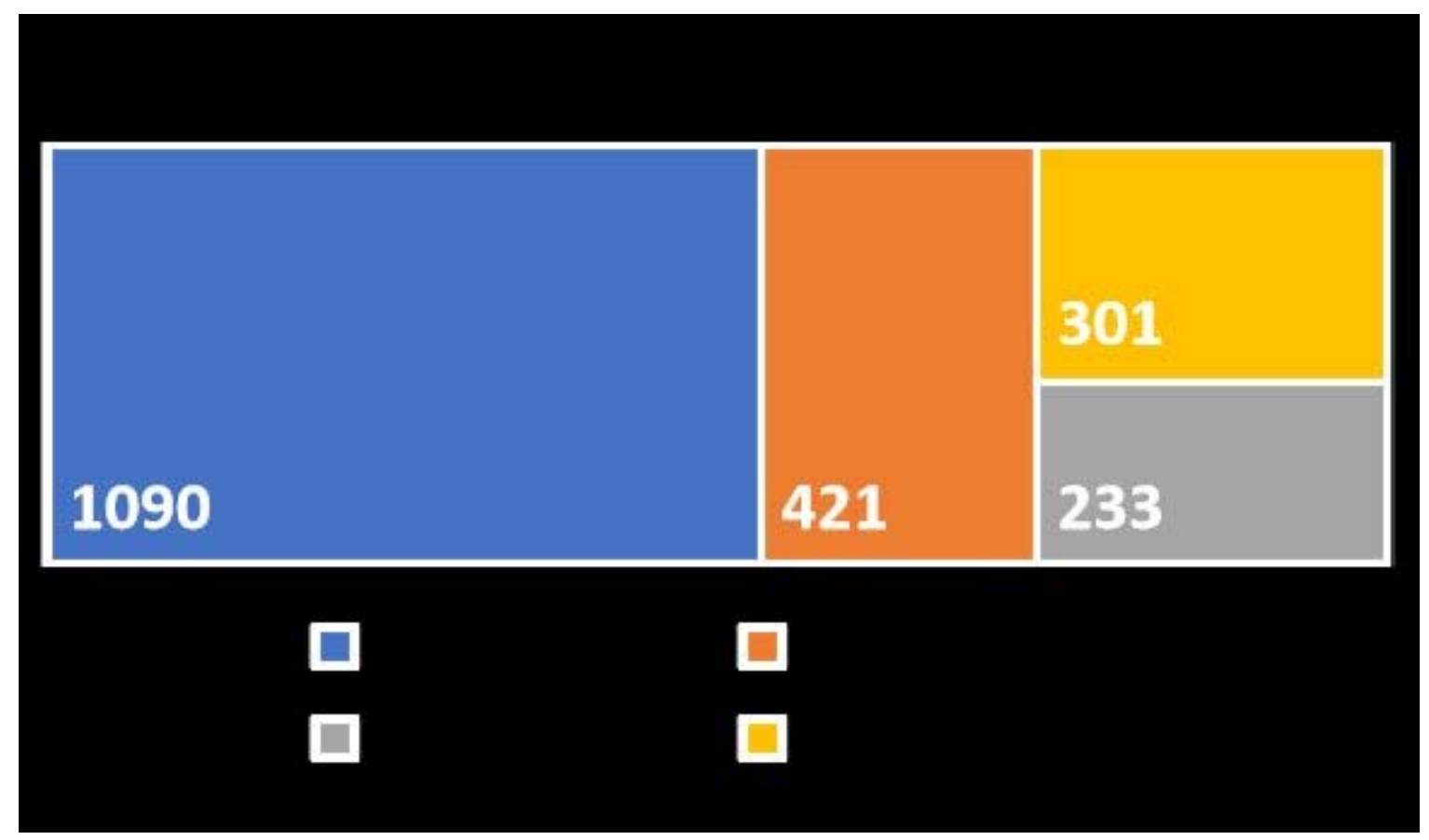

Figure 1.

Learned Publishing

\section{The bad}

The overall landscape, however, is not so optimistic.

More worrying signs emerge in Figure 1 when one looks at a large number of retraction initiators (53\%) and a small number of retractions (11\%) mutually agreed by the editors and the authors. 
Even though publishing retraction notes is a required practice, there is clearly a lack of consistency and consensus across journals in the writing of notice content.

For instance, the Committee of Publication Ethics (COPE), an established organization in publishing best practices with thousands of journals and publishers as members, does recommend the notes to disclose who is retracting the paper and their reasons, but this practice is not enforced well enough in practice.

Digging deeper, my study confirmed the obscurity in disclosing the person who first requested the retraction. This means that the $91 \%$ of retracted articles with adequate notes detailing the reasons still fall short of the COPE recommendation.

Knowing who initiated the retraction is not merely a matter of curiosity, but also one of acknowledgement. It benefits the authors who bravely admit their errors as much as their fellow researchers, who would look up to such candidness and realize that not all retracted papers are related to scientific misconduct.

The more retracted papers overlook this piece of information, the more suspicion they garner, and consequently, the more injustice is done to authors who honour the self-correcting spirit of science in coming forward.

\section{The ugly}

It takes courage to own up to one's mistakes as much as to be self-reflective of one's shortcomings.

A close-up analysis of 434 retracted articles shows the devastating loss of a limitation section in a research paper.

To write a limitation section is to self-acknowledge the weaknesses, and ultimately, represents an expression of humility and readiness for improvement. Yet, a strict categorization yields only 8 articles with this section, and even a more flexible approach that counts some kind of self-evaluated 'discussion' or 'future research directions' gives only 38 articles.

What is the correlation between these numbers and retraction? Remarkably, only 4 of the 38 retracted articles touch on weaknesses that to different extents reflect the actual reasons for withdrawing the articles.

By overlooking the ugly side of a research project, researchers are giving up the chance to re-examine it, an act that is essentially counter to the critical nature of scientific research.

The beauty in science does not lie in the eyes of the beholders as conventional wisdom would have it, but instead in our commitment to upholding its values and ideas.

It is thus important to also own up to one's ugliness in a project, a step that may prevent the future embarrassment of a more egregious error.

\section{Conclusion}

Retracted papers, no matter how undesirable they are, poke right at the heart of 
scholarly publishing.

A serious existential question arises regarding the health of the industry: What to do if an author is not coming forward to recall an inaccurate published paper, and the editorial board which accepts the paper is not aware of such inaccuracy or misconduct? Are we doomed to rely entirely on the heroic souls to be open about their shortcomings?

After all, scientists are humans, and humans are fallible. It is unavoidable that our research has its limitations and may be retracted under certain circumstances.

When a retraction happens, scientists and editors/publishers alike should cooperate to make the information as detailed and transparent as possible.

This article was originally published on the LSE Impact Blog. Read the original article.

\section{Tags:}

Citation:

Vuong, Quan-Hoang (2020). Retractions: the good, the bad, and the ugly. Nature Index (8 Sept. 2020). Retrieved from: https://www.natureindex.com/news-blog/academic-research-papers-scientists-gainretractions-the-good-the-bad-the-ugly 